\title{
Correction: Flow cytometric detection of leukemic blasts in cerebrospinal fluid predicts risk of relapse in childhood acute lymphoblastic leukemia: a Nordic Society of Pediatric Hematology and Oncology study
}

Maria Thastrup · Hanne Vibeke Marquart · Mette Levinsen · Kathrine Grell · Jonas Abrahamsson • Birgitte Klug Albertsen - Thomas Leth Frandsen · Arja Harila-Saari • Päivi Maria Lähteenmäki · Riitta Niinimäki • Cornelis Jan Pronk (1) - Aina Ulvmoen - Goda Vaitkevičienè - Mervi Taskinen - Kjeld Schmiegelow (1) on behalf of the Nordic Society of Pediatric Hematology and Oncology (NOPHO)

Published online: 8 April 2020

(c) Â@ The Author(s), under exclusive licence to Springer Nature Limited 2020

Correction to: Leukemia

https://doi.org/10.1038/s41375-019-0570-1

Following the publication of this article the authors noted an error in the following sentence which features in the "Results" section of the paper.

"Furthermore, the HR for CNS relapse was 4.7 (1.5-14.5) when the 124 CNSflow+cyto- patients were compared to the remaining $(P=0.008)$, whereas the HR for bone-marrow relapse was 1.5 (0.6-3.7)."

This has now been corrected in the PDF and HTML versions of this paper to read:

"Furthermore, the HR for CNS relapse was 4.7 (1.5-14.5) when the 104 CNSflow+cyto- patients were compared to the remaining $(P=0.008)$, whereas the HR for bone-marrow relapse was 1.5 (0.6-3.7)". 